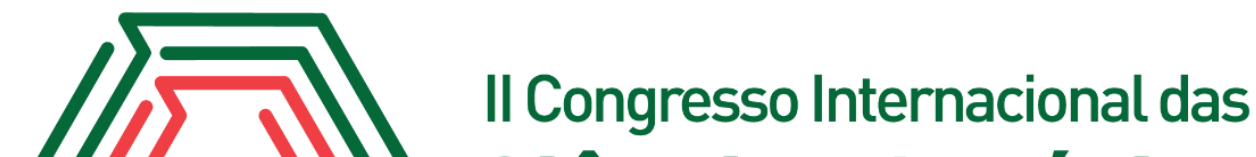 Ciências Agrárias COINTER - PDVAgro 2017
}

\section{CARACTERIZAÇÃO DE FRUTOS DE LARANJEIRAS, CULTIVADOS NO AGRESTE MERIDIONAL DE PERNAMBUCO}

\author{
Apresentação: Pôster \\ Daniela da Silva Andrade ${ }^{1}$; Maxwell Soares da Silva ${ }^{2}$; Raquel Maria da Silva ${ }^{3}$; Mairon \\ Moura da Silva ${ }^{4}$
}

\section{Introdução}

O primeiro produtor mundial de citros e o maior exportador de suco concentrado congelado de laranja é o Brasil, dominando cerca de $87 \%$ do mercado internacional existente (EMBRAPA, 2014). A laranja ocupa lugar de destaque na citricultura brasileira, onde a produção é estimada em 18,7 bilhões de toneladas. A produção de citros na região Nordeste obteve um crescimento ao longo do tempo, apoiando-se principalmente na área plantada e no aumento da produtividade.

Embora os citros estejam entre as espécies mais pesquisadas, os estudos sobre a fisiologia da planta relacionados com a produção, tratos culturais, pragas e doenças, ainda têm sido de fundamental importância para a avaliação do crescimento e desenvolvimento dos frutos, e consequentemente contribuirão para um planejamento mais adequado da colheita (NASCIMENTO et al., 2012). As informações que envolvem o crescimento e o desenvolvimento dos frutos são importantes, pois são processos que influenciam diretamente na qualidade final dos frutos. $\mathrm{O}$ conhecimento do comportamento fenológico dos citros contribui para o controle e definição do ciclo reprodutivo das espécies, mantendo o equilíbrio entre a produção e a época de menor oferta nas regiões produtoras para obtenção melhor preço do mercado (NASCIMETO et al., 2012).

Portanto este trabalho tem como objetivo avaliar as características físicas e químicas de 15 variedades de laranjas, considerando assim seu desenvolvimento fenológico de crescimento.

\section{Fundamentação Teórica}

\footnotetext{
${ }^{1}$ Agronomia, Universidade Federal Rural de Pernambuco - UFRPE/UAG, daniela5191@hotmail.com

${ }^{2}$ Agronomia, Universidade Federal Rural de Pernambuco - UFRPE/UAG, maxwell-soares@outlook.com

${ }^{3}$ Agronomia, Universidade Federal Rural de Pernambuco - UFRPE/UAG, raquel.maria18@hotmail.com

${ }^{4}$ Professor adjunto, Universidade Federal Rural de Pernambuco - UFRPE/UAG, maironmoura@hotmail.com
} 
A principal característica da região Nordeste é sua multiplicidade de clima e solos, que a torna diferente das demais regiões e com múltiplas aptidões para o mercado do agronegócio, sendo a história da citricultura nordestina desencadeada a partir da década de 70. O Nordeste mostra diversas vantagens para o cultivo de citros como a proximidade dos grandes mercados importadores (Europa e Estados Unidos) (PASSOS et al.,2006).

As plantas cítricas por serem de clima tropical e subtropical, apresentam frutos que se adequam as condições de calor e alta umidade, com elevada produção de suco e altos teores de açúcar. A temperatura do ar e a disponibilidade de água tem influência em todas as fases de desenvolvimento das plantas cítricas, sendo o principal fator condicionante da cor interna e externa do fruto (LORENZI et al., 2006).

Características como coloração externa intensa e uniforme, ausência de danos ou imperfeições na casca, facilidade de descascar, tamanho, ausência de sementes, rendimento de suco, e relação equilibrada entre sólidos solúveis e acidez são fundamentais para o mercado interno e externo do fruto "in natura" (PEREIRA et al., 2006). As modificações mais evidentes na maturação dos frutos são aquelas que se processam no conteúdo de sólidos solúveis, acidez titulável e na coloração da casca.

\section{Metodologia}

O experimento foi implantado em um pomar com dez anos de idade na Estação experimental de Brejão do Instituto Agronômico de Pernambuco, localizado a 18 km de Garanhuns. Tendo um clima seco subsumido, temperatura do ar média mensal que varia de 17 a $22^{\circ} \mathrm{C}$ ao longo do ano, com amplitude térmica média mensal variando de 7 a $12^{\circ} \mathrm{C}$ e precipitação anual entre 850 a $1.300 \mathrm{~mm}$.

O material vegetal foi fornecido pela EMBRAPA Mandioca e Fruticultura (CNPMF) e implantado em maio de 2006. Foram avaliadas 15 cultivares de laranjeiras (Bahia 101, Baianinha 03, Hamlin 02, Lima; Rubi, Sunstar, Pineapple, Pêra D6, Pêra D9, Pêra D12, Valência Tuxpan, Westin, Midsweet, Natal e Salustiana), sob os respectivos portas-enxerto CLEO-SW-264, CLEO-SW-264, LVK-CLEO-264, LVK-CLEO-264, LVK-CLEO-264, LVK-CLEO-264, LVK-CLEO-264, LVKCLEO-264, LCR-LVK-CLEO, LVK-CLEO-226, LVK-CLEO-226, LVK-CLEO-264, LVK-CLEO264, LCR-CLEO-256, LCR-CLEO-264, LVK-264, LVK-SW-264, CLEO-264.

$\mathrm{O}$ delineamento experimental foi em blocos ao acaso e arranjo fatorial (variedades e fases fenológicas), com duas repetições. Cada parcela foi composta por seis plantas espaçadas 6 x $4 \mathrm{~m}$.

As avaliações nos frutos foram realizadas em três fases de desenvolvimento fenológico, no período entre os meses de novembro de 2016 e de dezembro de 2016. As fases fenológicas estudadas 
compreenderam a Fase 8 - fruto verde próximo do tamanho final; Fase 9 - fruto na mudança de cor verde para amarela; Fase $10-$ Ratio $\geq 12$.

Para as análises físicas, físico-químicas e químicas foram colhidos quatro frutos de cada planta, aleatoriamente, nos quatro quadrantes da planta, na parte externa e mediana da copa. A colheita dos frutos ocorreu conforme chegavam à fase de maturação. As avaliações físicas realizadas nos frutos foram: peso do fruto $(\mathrm{g})$; diâmetro longitudinal e transversal do fruto ( $\mathrm{mm})$; espessura da casca $(\mathrm{mm})$; espessura do endocarpo $(\mathrm{mm})$ e peso de sementes por fruto.

As avaliações físico químicas e químicas foram sólidos solúveis, expressos em ${ }^{\circ}$ Brix, e teor de vitamina C (ácido ascórbico).

Os resultados foram submetidos a análise de variância e teste de média com auxílio do Programa SAEG-UFV.

\section{Resultados e Discussões}

Verificou-se redução no peso médio dos frutos de acordo com as fases fenológicas, exceto nas variedades Bahia 101, Salustiana e Sunstar esta característica pode ser uma consequência de altas temperaturas e baixa pluviosidade encontradas no período das análises, onde houve perdas de água por evapotranspiração de compostos do fruto, na qual segundo Lorenzi et al., (2006) diz que fatores climáticos como a temperatura e a disponibilidade de água possui importância em todas as fases de desenvolvimento das plantas em estudo, afetando características como cor e peso de frutos. Apenas as variedades Bahia e Midsweet demonstraram pesos de 172,5g e 165g respectivamente estando de acordo com Domingues et al. (2003), na qual diz que os frutos mais consumidos no mercado in natura possuem peso de $150 \mathrm{~g}$. As variedades Bahia 101, Valência Tuxpan e Midsweet apresentaram peso de fruto próximo a $150 \mathrm{~g}$ ideal para frutos de mesa.

A espessura da casca e do endocarpo reduziram com o avançar das fases fenológicas, exceto para a variedade Bahia 101. A redução da espessura da casca facilita o descascamento dos frutos destinados à mesa, tornando-o mais atraente para os consumidores. Para a espessura do endocarpo foi possível verificar estatisticamente que as variedades Hamlin 02, Lima, Rubi, Sunstar, Pineapple, Pêra D6, Pêra D9, Pêra D12, Valência Tuxpan, Westin, Midsweet, Natal e Salustiana apresentaram na fase 9 uma espessura superior as demais fases, sendo uma característica do fruto em relação a seu enchimento, o que não ocorreu na variedade Baianinha 03 nas fases 8 e 9 e redução na fase 10.

Em relação ao peso das sementes presentes nos frutos avaliados foi possível observar que as variedades Hamlin 02, Lima, Rubi, Sunstar, Pineapple Pêra D6, Pêra D9, Pêra D12, Valência Tuxpan, 
Westin, Midsweet, Natal e Salustiana apresentaram maior valor na fase inicial de desenvolvimento (fase 8), tendo seu número reduzido nas fases finais (fases 9 e 10), exceto a Bahia 101 e Baianinha 03 que não apresentaram diferença significativa com avanço das fases. A ausência ou baixo número de sementes é o desejável para os frutos cítricos destinados à mesa pelo consumidor (SANTOS et. al., 2010).

O diâmetro transversal dos frutos aumentou com a maturação dos frutos, exceto para a variedade Bahia 101 que permaneceu constante. A variedade Baianinha 03 nas fases 9 e 10 apresentou um crescimento em relação a fase 8, enquanto nas demais variedades a fase 9 apresentou maior tamanho tendo um decréscimo na fase final de maturação (fase 10). Para o diâmetro longitudinal do fruto apenas a variedade Bahia 101 mostrou estabilidade no avanço das fases, já as demais variedades a altura do fruto diminuiu significativamente.

Para as análises químicas observou-se que as variedades estudadas apresentaram valores de sólidos solúveis maiores na fase final de desenvolvimento (fase 10), exceto a variedade Bahia 101 que não apresentou diferença significativa. Apenas as variedades Pêra D9 e D12 apresentaram teores abaixo de $10^{\circ}$ Brix e abaixo dos observados por Yamada et al. (2012). No decorrer do processo de maturação dos frutos podem acontecer diversas mudanças na cor da casca; no aroma; no sabor; aumento dos teores de sólidos solúveis, sobretudo açúcares; e de compostos nitrogenados. A qualidade e composição dos frutos de laranjas devem representar as características típicas de cada variedade.

Frutos imaturos e que apresentam teor de sólidos solúveis menor que $10^{\circ} \mathrm{Brix}$, murchos devido falta de turgor causada por desordem fisiológica ou desidratação, e não suculentos, influenciam na comercialização por não aceitação pelos consumidores (CEPEA, 2013).

Os valores de vitamina $\mathrm{C}$ reduziram com a maturação em todas as variedades estudadas. $\mathrm{O}$ teor de vitamina $\mathrm{C}$ varia de acordo com a região, clima, época de colheita, fase fenológica e variedade estudada.

\section{Conclusões}

O acompanhamento da maturação dos frutos indicaram que ocorreu uma redução no peso médio dos frutos, espessura da casca, peso de sementes e diâmetro longitudinal, e um aumento na espessura do endocarpo e diâmetro transversal do fruto no avanço das fases fenológicas. Para as 
análises químicas os resultados mostraram um aumento de sólidos solúveis e redução de vitamina $\mathrm{C}$ conforme o fruto atingia o ponto de maturação.

\section{Referências}

CEPEA- Centro de Estudos Avançados em Economia Aplicada-ESALQ/USP. 2013. Disponível em: http://cepea.esalq.usp.br/citros/cadeia_citros.pdf. Acessado em: 25 de Setembro de 2013.

DOMINGUES, Edson Tobias. Caracterização morfológica, agronômica, isoenzimática e por Rapd de variedades de laranja doce-Citrus sinensis (L.) Osbeck. 2003. Tese de Doutorado. Escola Superior de Agricultura Luiz de Queiroz na Universidade de São Paulo.

EMBRAPA, $2014 . \quad$ Disponível em: www.embrapa.br/publicações/Limoeirofino:frutacitricaacidadogruposiciliano Acesso em: 26 jan. 2017.

LORENZI, H.; BACHER, L.; LACERDA, M.; SARTORI, S. Frutas brasileiras e exóticas cultivadas. Instituto Plantarum de Estudos da Flora, São Paulo, 2006. p.640.

NASCIMENTO, S. S.; BASTOS, D. C.; NASCIMENTO, F. S. S.; PASSOS, O. S.; Fenologia do Limoeiro 'Eureka' no Vale do São Francisco; XXII Congresso Brasileiro de Fruticultura, (2012).

PASSOS, O. S.; SOUSA, C. A. F.; SOARES FILHO, W. S. Alternativas de porta-enxertos de citros no Nordeste do Brasil. Embrapa Mandioca e Fruticultura Tropical, Dezembro de 2005 (folder). Aput:

POMPEU JÚNIOR, J e BLUMER, S., Laranja, Cordeirópolis, v.27, n.2 p. 341-354, 2006.

PEREIRA, Márcio Eduardo Canto et al. Procedimentos pós-colheita na produção integrada de citros. Cruz das Almas, Embrapa Mandioca e Fruticultura Tropical, 2006.

SANTOS, D.; MATARAZZO, P. H. M.; SILVA, D. F. P.; SIQUEIRA, D. L.; SANTOS, D. C. M.; LUCENA, C. C. Caracterização físico-química de frutos cítricos apirênicos produzidos em Viçosa, Minas Gerais. Revista Ceres, Viçosa, v. 57, n.3, p. 393-400, mai/jun, 2010.

YAMADA, C. S. et al. Qualidade de laranja "pêra" de mesa comercializada na CEAGESP, entreposto de Ribeirão Preto - SP. IV Congresso de Iniciação Científica - Ribeirão Preto: Ituverava, 2012. 